\title{
Harnessing risk to guide mine rock stockpile closure and long-term cost reduction
}

\author{
SC Lamoureux Okane Consultants Pty Ltd, Australia \\ MA O'Kane Okane Consultants Inc., Canada
}

\begin{abstract}
Identifying, understanding, communicating, and managing potential and actual risks associated with mine rock stockpiles (MRSs) closure are effective tools to guide technical studies, inform management decisions and facilitate cost minimisation for closure. Okane Consultants (Okane) Pty. Ltd. have implemented these tools at an iconic Pilbara mine site for nearly three decades. Historic dumping practices $(<1990 s)$ at the site resulted in MRS structures that did not limit sulphide mineral oxidation, as interactions between its principal constituents, mainly oxygen and to a lesser extent water were not controlled. Evidence of potentially acid forming (PAF) material reactivity was recognised early resulting in the identification of potential risks of high internal temperatures and acid metalliferous drainage (AMD) thus guiding preliminary technical studies.

Preliminary studies included MRS drilling programs to quantify the structure, reactivity and hydrology of MRSs. During these programs MRSs were instrumented with gas and moisture sensors to quantify MRS reactivity and moisture conditions in response to environmental factors over time. Instrumented cover systems were also tested as a means of limiting oxygen ingress and net percolation (NP). These investigations led to significant advancements in the understanding of the MRS conditions, construction, sulphide oxidation, and associated risks.

With closure of a potentially reactive MRS scheduled within five years (year 2023) learnings from preliminary investigations were used to inform managers during a risk workshop focusing on MRS reshaping and the construction of a cover system to limit internal reactivity and AMD. Key workshop outcomes were the need to further quantify the moisture status of the MRS to determine its propensity toward $A M D$, and the identification that vegetation will be key to limiting NP into the final landform through transpiration thus limiting AMD. In this case study risk was effectively identified and communicated to provide a MRS closure solution specific to the company's closure criteria and risk profile ultimately resulting in long-term cost reduction for closure.
\end{abstract}

Keywords: waste rock dump, risk, mine closure

\section{$1 \quad$ Setting the scene}

Mining tenements (live and pending) cover $91.8 \%$ of Western Australia's Pilbara region (Environmental Protection Authority 2014). Western Australia iron ore sales attained a record 826 million tonnes in 2017-2018, with royalty revenue of approximately AUD 4.48 billion paid to the Australian government (Department of Mines and Petroleum 2018). However, the economic ore being sold to external markets result in large amounts of uneconomic low-grade ore and non-mineralised rock placed into large mine rock stockpiles (MRSs) on the domestic land surface. The formation of MRSs creates new landforms that can pose substantial environmental and public health risks to local and downstream receptors if not properly constructed, managed, and rehabilitated.

Historically little attention was given to the characterisation, placement, and construction of MRSs. The level of understanding pertaining to MRSs and its internal processes coupled with less stringent historical regulatory frameworks has in many cases resulted in legacy issues such as acid and metalliferous drainage (AMD), surface erosion, gas release, internal heating, and combustion of waste materials (Commonwealth of 
Australia 2019). In some instances, legacy issues have resulted in significant environmental and social impacts to downstream receptors (Singh 1999; Commonwealth of Australia 2019). Currently the public generally accept mining as an essential industry, but that it tends to be in opposition to the preservation of natural environments. In many instances, this public perception is due to historical mining practices that did not always consider environmental risks and impacts as part of their mining and processing operations (Singh 1999). Therefore, companies operating today that hold legacy sites of environmental and social concern are highly motivated to lower their risk profile and increase their social licence to operate by effectively identifying, communicating, and managing potential and actual risks associated with legacy MRSs. This case study highlights the proactive steps taken by the management team of an iconic Pilbara mine site (The Mine) from identification through to management of the risks associated with a historic MRS.

\section{What were the risks and how were they understood?}

Knowledge pertaining to AMD management was limited prior to the 1990s resulting in MRS structures that did not limit sulphide mineral oxidation at many sites globally, and at The Mine. Interactions between principal constituents of AMD, mainly sulphide minerals in waste rock, oxygen and to a lesser extent water, were not controlled resulting in AMD drainage (Figure 1). These were characterised by a lack of AMD prediction through geochemical testing, historic dumping practices, and lack of engineering controls to limit oxygen ingress and water percolation.

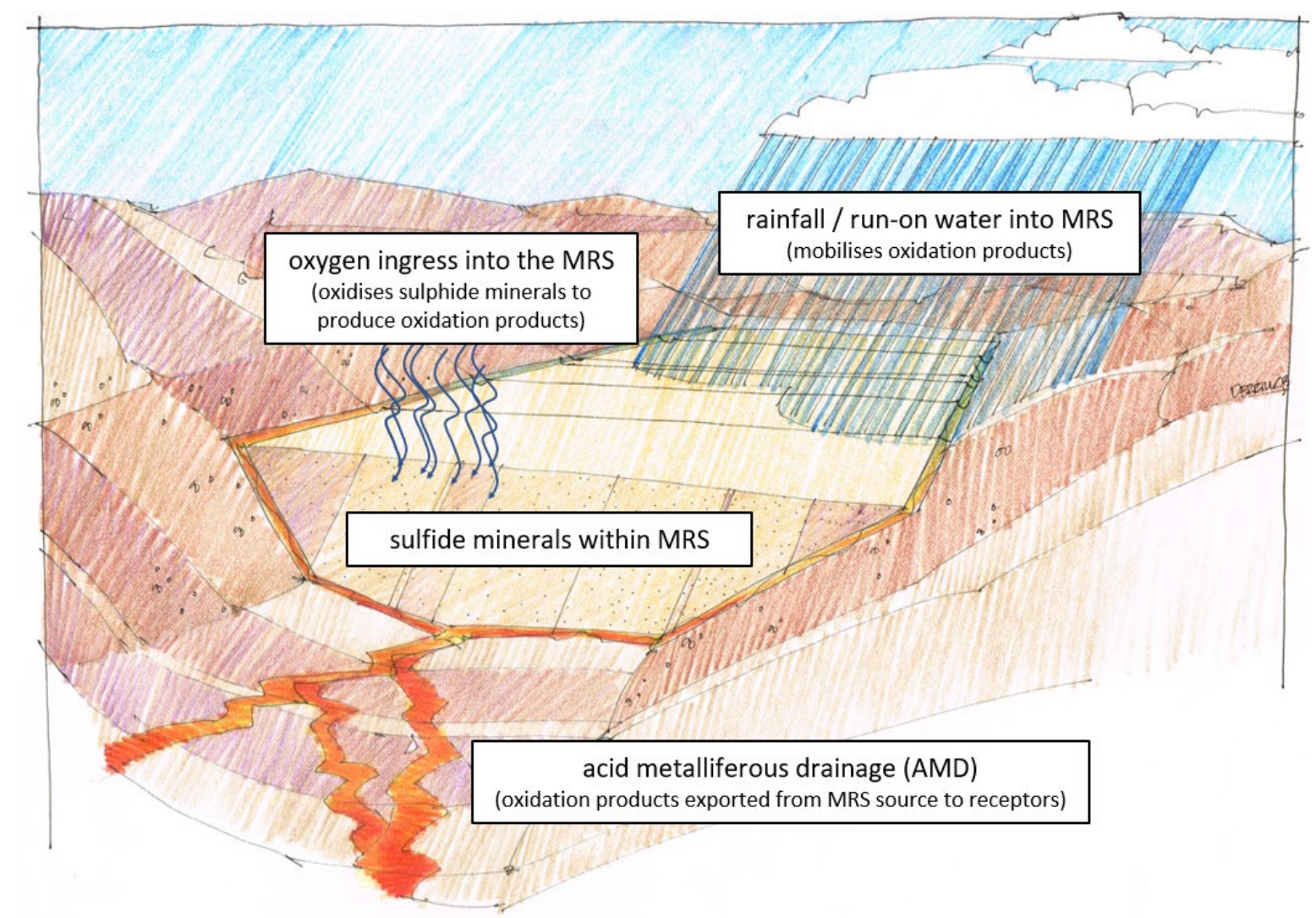

Figure 1 Generalised acid metalliferous drainage (AMD) formation within a mine rock stockpile (MRS)

\subsection{AMD prediction and historical dumping practices}

At The Mine several years of end tipped co-mingled finer and coarser material from high tip heads resulted in segregation of waste rock and the formation of a significant coarser grained rubble layer at the base of the legacy MRS in question (Figure 2). Little record of spatial data of dumped potentially acid forming (PAF) and non-acid forming (NAF) material, and dumping history existed. Evidence of waste rock scheduling to manage the oxidation of PAF waste coming from the pit was not found. 
Segregation of waste rock provided flow paths for advective gas movement into the MRS. The ingress of oxygen resulted in the oxidation of sulphide baring waste minerals producing acidity within the MRS. After large rainfall events the acidity was mobilised through net percolation (NP) of water, the visualised as AMD seepage emanating from the toe of the MRS. Heating within the MRS was also apparent as gas/vapour discharge was observed at the surface.

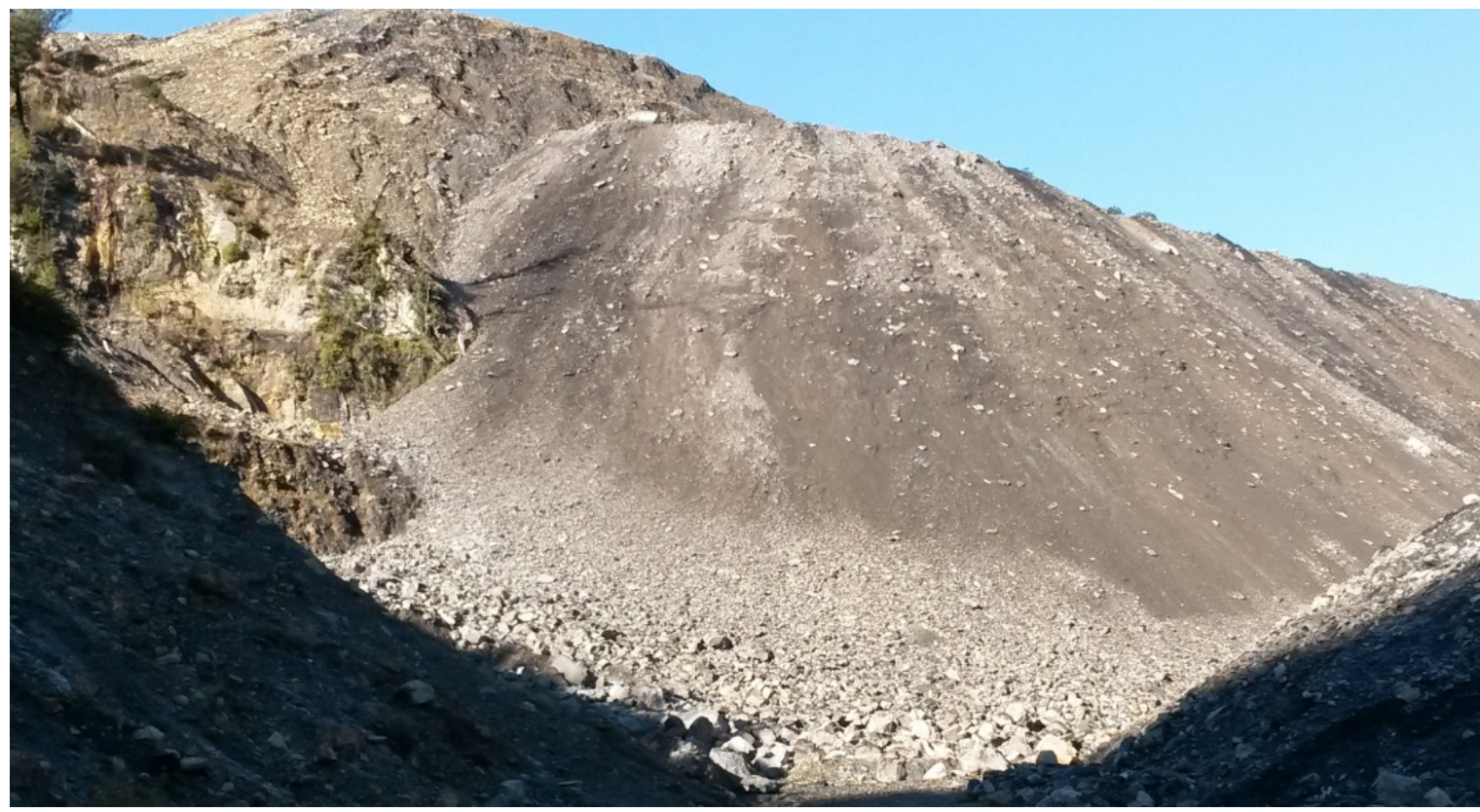

Figure 2 Grain size segregation associated with end-tipping from approximately $120 \mathrm{~m}$ high (Cavanagh et al. 2018)

\subsubsection{Understanding the risk}

The identification of the AMD and internal heating risks from the legacy MRS at The Mine prompted the inception of preliminary studies to fully understand the risks and their root causes. Okane were engaged to undertake studies to quantify the structure, reactivity and hydrology of the legacy MRS to recommend and design effective management measures to control AMD.

A drilling program to quantify the structure, reactivity and hydrology followed. The program set out to characterise geochemical and physical nature of material within the MRS through a material characterisation and analysis program at Okane's Perth Laboratory. The objective of the characterisation program was to build an understanding of material characteristics within the MRS in order to understand and model its reactivity. The characterisation program occurred concurrent to a downhole MRS instrumentation and monitoring program which resulted in the installation of several sensor types to monitor In situ moisture conditions, oxygen concentration, and temperature (Figure 3). The objective of the instrumentation and monitoring program was to build an understanding of internal hydrological properties, oxygen concentrations, and temperatures. Coupling internal condition data with the spatial data from the material characterisation program allowed for evaluation of in situ PAF waste materials control on AMD production, and potential discharge to the surrounding environment. 


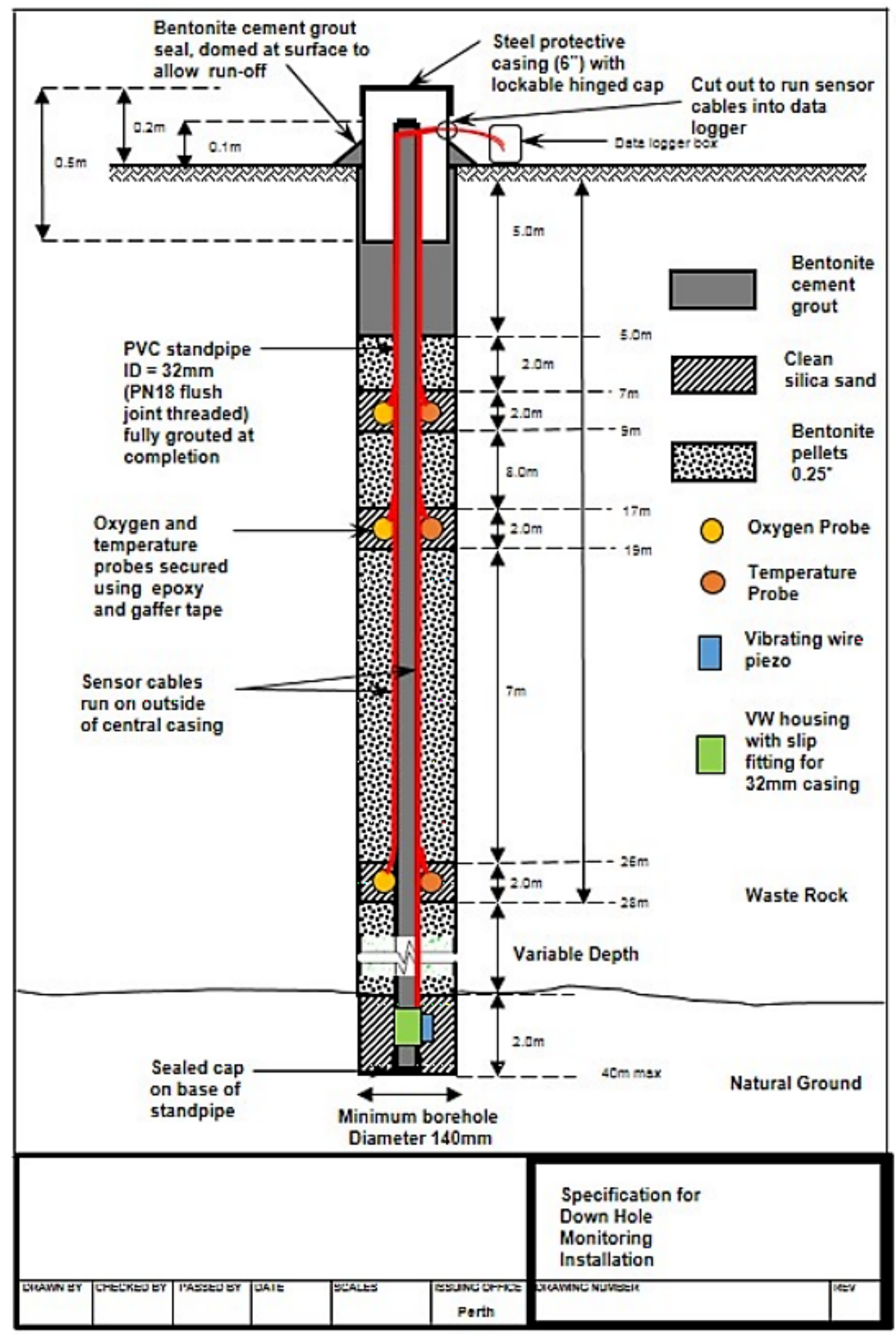

Figure 3 Typical downhole mine rock stockpiles installation (Pearce \& Barteaux 2014)

Results from the material characterisation program and internal dump conditions substantially increased the understanding of internal MRS controls on AMD production. A summary of the key findings from these investigations are presented in Table 1. 


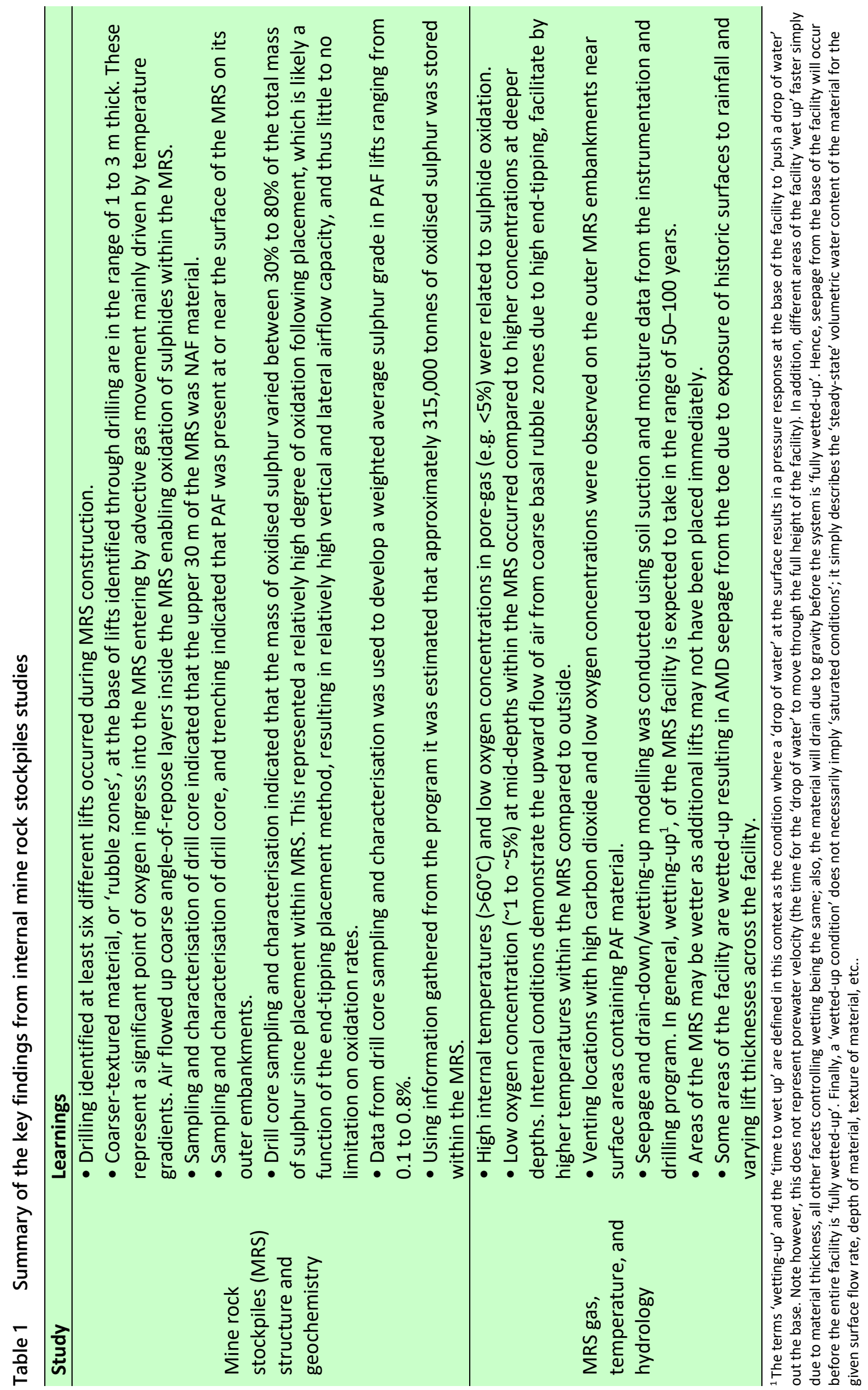


After the initial identification of issues related to AMD prediction and historic dumping practices Okane was able to work with The Mine to effectively quantify and understand the associated risks. Study results at the site highlighted the importance of effective PAF waste management and scheduling to manage oxidation. It also highlighted the need to design and construct MRSs to prevent the advection of oxygen as a source control for AMD. Moreover, the analysis of internal dump moisture conditions provided valuable insights into the magnitude and timing of AMD seepage, which can in turn be used to inform AMD management decisions translating into long-term cost savings.

\subsection{Lack of mine rock stockpiles engineering controls for oxygen and water}

PAF scheduling and management, and progressive construction and rehabilitation currently being employed at The Mine were not historically in effect like most historic mines. Prior to 1995 it was assumed that AMD would not be an issue at The Mine due to the arid conditions and high potential evaporation resulting in no requirements for engineered controls on NP and oxygen ingress. However, following heavy rainfall in 1995 and subsequent AMD seepage, it was determined that engineering controls to reduce NP and oxygen ingress was required.

The historic lack of PAF waste management and scheduling resulted in an overall lack of engineering controls to limit oxygen ingress and NP at the site. Large tip heads and lift heights resulted in lower compaction and longer exposure time of PAF and NAF lifts resulting higher rates of oxygen ingress and NP. Without engineering controls such as cover systems the exposed exterior of the MRS resulted in oxidation of sulphide baring waste minerals producing acidity within the MRS. Exposure of the MRS surfaces also resulted in increased NP leading to AMD discharges at the base of the structure.

\subsubsection{Understanding the risk}

Okane were engaged to provide guidance on engineering controls to manage AMD generation and seepage from the legacy MRS at The Mine. The Mine's base assumption for MRS rehabilitation was the application of store-and-release cover systems across its MRSs for the purpose of managing AMD risks. Beginning in 1998 several instrumented cover systems of various thicknesses and material types, and vegetated test plots were constructed and monitored to measure their effectiveness in managing AMD (Figure 4).

Cover systems were instrumented with suction and volumetric water content sensors to quantify soil moisture conditions and NP, a meteorological monitoring station was also installed. Over time refinement of the cover system conceptual model resulted in construction of other instrumented cover system field trials in 2002 with the addition of oxygen sensors. These cover trials have resulted in a 20-year continuous dataset, arguably one of the longest and largest cover system datasets of its kind.
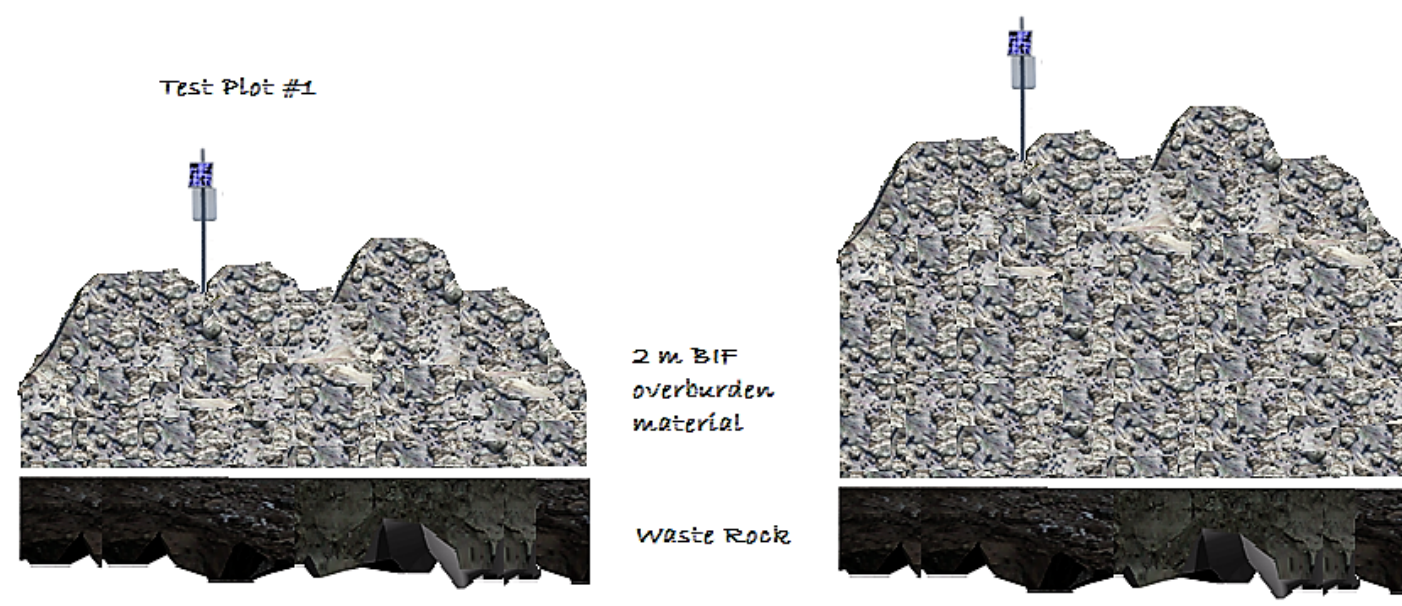

$5 \mathrm{mB}$ overburdien material

Waste Rock

Figure 4 Cover system configuration constructed in 1995 
Building off learnings from previous studies undertaken at The Mine since 1997 (e.g. material characterisation and field performance monitoring), cover system numerical modelling was completed to inform The Mine on the optimal approach and/or conditions to minimise risk of PAF material placed in ex-pit MRSs (both top and sloping surfaces). The integration of field studies and numerical modelling focused on enhanced management of gas and water ingress to PAF material within MRSs, as well as the fate of any salts near the surface of the MRSs that had the potential to adversely impact closure performance.

The conceptual model of cover system performance and NP requirements used in the modelling scenarios were refined using the International Network for Acid Prevention (INAP) (2017) cover system design framework hierarchy for oxygen and moisture control (Figure 5). Steps within the hierarchy represent site attributes (climate, geology/materials, or topography) that produce or constrain cover system design alternatives to achieve performance objectives (INAP 2017). The climate filter allowed for the identification of dominant physical processes that could be exploited and/or enhanced at The Mine. Therefore, the cover system design alternatives were modified to suit the climatic setting. The Köppen-Geiger (Peel et al. 2007) classification system helps characterise precipitation and temperature on a seasonal and annual basis. Both parameters were integral to understanding key physical processes that control water balance and consequently influence NP and oxygen ingress.

Completing the framework provided increased confidence that store-and-release cover alternatives relying on materials of sufficient thickness and texture would successfully limit NP, oxygen, and salt rise at The Mine. After all design filters within the INAP (2017) framework were completed, the five cover system alternatives were modelled while integrating the 20-year dataset and the conceptual understanding of the site to provide increase confidence that the risk would be successfully managed.

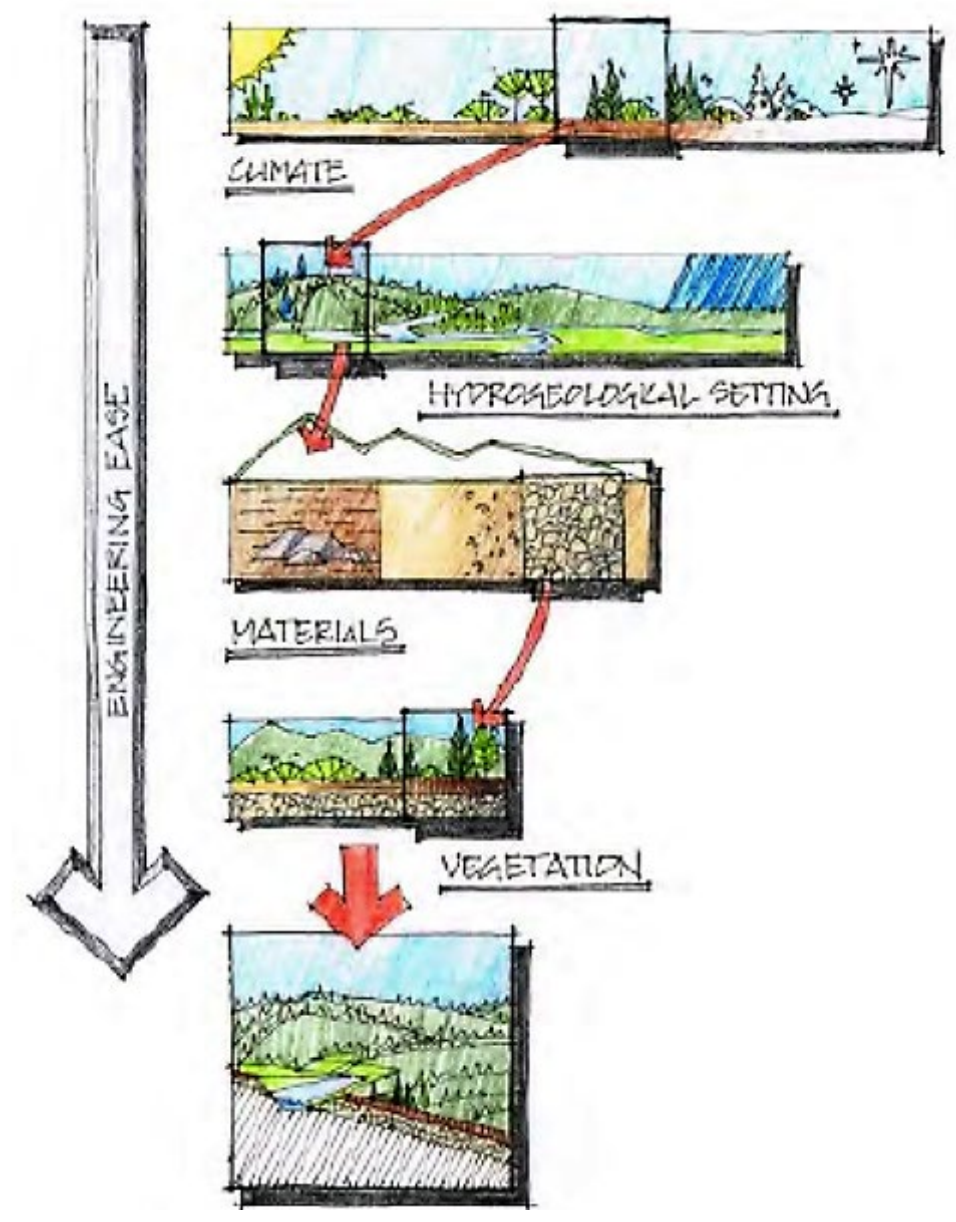

Figure 5 Conceptual cover system design framework portraying four filters for climate, hydrogeology, materials, and vegetation (INAP 2017) 
The instrumented cover systems and modelling studies drastically increased the understanding of cover system controls on AMD production and mobilisation at The Mine. A summary of the key findings from these investigations are presented in Table 2.

Table 2 Summary of the key findings from cover system performance monitoring and cover system alternatives monitoring

\begin{tabular}{ll}
\hline Study & Learnings \\
\hline & - NP is occurring which results deeper water recharge within the cover system and \\
mine rock stockpile (MRS). \\
- Water recharge within the cover and MRS increases during the wet-season, after \\
large rainfall events, and for overall wetter climate years. \\
- The majority of near surface moisture cycling is occurring within the upper $3 \mathrm{~m}$ to \\
Cover system & 5 m of the cover surface, while NP or recharge is occurring bellow 5 m. \\
performance & - A reduction in NP rate due to placement of a cover system will increase the MRSs \\
monitoring & 'time to wet up' and decrease the overall seepage rates. \\
& - The Mine experiences challenges with rehabilitation and vegetation regrowth on \\
& MRS surfaces. \\
& - Revegetation of MRS surfaces are strongly related to near surface moisture \\
& availability. \\
& - NP (deep MRS recharge) could be reduced from a bare surface NP rate of \\
approximately $35 \%$ to an NP rate of approximately $10 \%$ of average annual rainfall \\
for all cover alternatives with $50 \%$ plant cover, $80 \%$ of plant roots within the first \\
0.5 m of the cover, a max rooting depths of 2 m, and plant water extraction \\
occurring from $100 \mathrm{kPa}$ to $1,500 \mathrm{kPa}$. \\
- A $5 \mathrm{~m}$ cover consisting of two $2.5 \mathrm{~m}$ paddock dumped NAF waste layers of material \\
alternatives \\
modelling
\end{tabular}

After the initial identification of issues related to engineering controls on oxygen and water entry into the MRS in question, Okane was able to work with The Mine to effectively quantify and understand the mechanisms driving risk. Study results at the site highlighted the need to design and construct effective vegetated cover systems to prevent oxygen ingress as a source control for AMD, and limit NP to control mobilisation of acidity already within the MRS. Moreover, the analysis of cover system performance provided valuable insights into the magnitude, timing, and concertation of potential AMD seepage. Effectively communicating this information to management teams can in turn be used to inform AMD management decisions translating into long-term cost savings.

\section{Communicating the risk}

Effective risk management is core to any mining company's operation, and in most cases, this can only be achieved through effective risk communication. Many risk frameworks exist (e.g. Bow-Ties, SWIFT, Delphi, HAZOP), however; few are directly applicable to the closure of MRSs, consider offsite impacts, and regulatory requirements applicable to engineered and natural systems, incorporate risk profile flexibility, are multidisciplinary, and integrate a base case design or understanding that can be refined and improved. Okane has found the use of failure modes and effects analysis (FMEA) to be the most comprehensive and efficient framework to delivering MRS closure guidance and long-term closure cost reduction. 
An FMEA is a top-down / expert approach to risk identification, quantification, mitigation, identification and prioritisation. Its value and effectiveness depend on having experts with the appropriate knowledge and experience to participate in the evaluation during which failure modes are identified, risks estimated, and appropriate mitigation measures proposed. It is therefore essential that the evaluation team include representatives who understand the site-specifics, which include geotechnical, hydrological and environmental conditions. In addition, it is important that the sites' context is considered in terms of on and offsite impacts, and regulatory requirements applicable to the engineered and natural systems and their surroundings.

An FMEA provides evaluators with the ability to perform a systematic and comprehensive evaluation of potential failure modes of the design / plan in order to identify potential hazards. The FMEA can also be used to evaluate potential for failures in the site's rehabilitation that could result in environmental impacts, legal and other obligations, effects to reputation with stakeholders, and human health and safety concerns. A risk profile can be developed for each of these concern areas. Once the failure modes and measures with the highest risk have been identified, it is possible to consider mitigation or alternative designs to reduce risks. FMEAs are therefore an essential part of any risk- and liability-reduction program.

The environmental community regularly uses this process for conducting environmental risk assessments. Engineers use this type of method to assess the risk of engineered systems. Mining companies can use this assessment method to evaluate the risk that their rehabilitation and closure plans impose on the surrounding environment, workers and the public.

\subsection{Scope and objectives setting}

In this case study, at the time of the FMEA The Mine's life-of-mine (LOM) was 30 years, while closure of the MRS in questions was scheduled within five years. The Mine already had a conceptual landform design (the base case), cover system design (discussed in previous sections) and has an obligation to meet its closure criteria of safe, stable, non-polluting, and re-vegetated to species resembling the surrounding environment for its final landforms. Learnings in Tables 1 and 2 from studies beginning in 1997 were essential sources of information relating to the identification, understanding, and quantification of the risks associated with the MRS in question. They were used to concisely inform FMEA participants on the issues at hand and used to guide the FMEA to effectively communicate the risk to achieve effective management outcomes.

To achieve the closure criteria a significant amount of reshaping and haulage of NAF material was required. The significant NAF haulage requirements in conjunction with the current mining schedule indicated that if completion of earthwork did not occur within five years, the cost of handling and closure would increase by 25 times due to increased haulage distances. One of the main objectives of the FMEA was to identify the main failure modes that could hinder the closure of the landform resulting in substantially higher closure costs, and to identify how to remedy identified potential failures within the five-year time frame. Therefore, the FMEA successfully captured both the closure and capital expenditure requirements throughout the analysis.

Main points of consideration during the FMEA (amongst others) were:

- Reshaping of the MRS in question and integration with other MRSs.

- Evaluation of the base case landform design and cover system for closure within five years.

- Would the base case landform and cover system design achieve closure objectives.

- The management of water quality for surface water drainage and groundwater associated with the MRS.

\subsection{Time frame definition}

To conduct the risk assessment, it was essential to agree upon a time frame over which likelihoods were evaluated. During this FMEA short-term (planning, execution, and adaptive management / monitoring phases) was 0-30 years (Figure 6). Long-term (proactive phase and a reactive phase) was 30-200 years (Figure 6). The 30-year short-term time frame was primarily defined by the LOM in that execution of the 
closure design for the MRS would be conducted using existing operational scale equipment, and that personnel would be onsite to conduct monitoring and maintenance for adaptive management. They were agreed to during the FMEA workshop to ensure workshop participants were of the same understanding when the commonly used subjective terms 'short-term' and 'long-term' were utilised during the workshop.

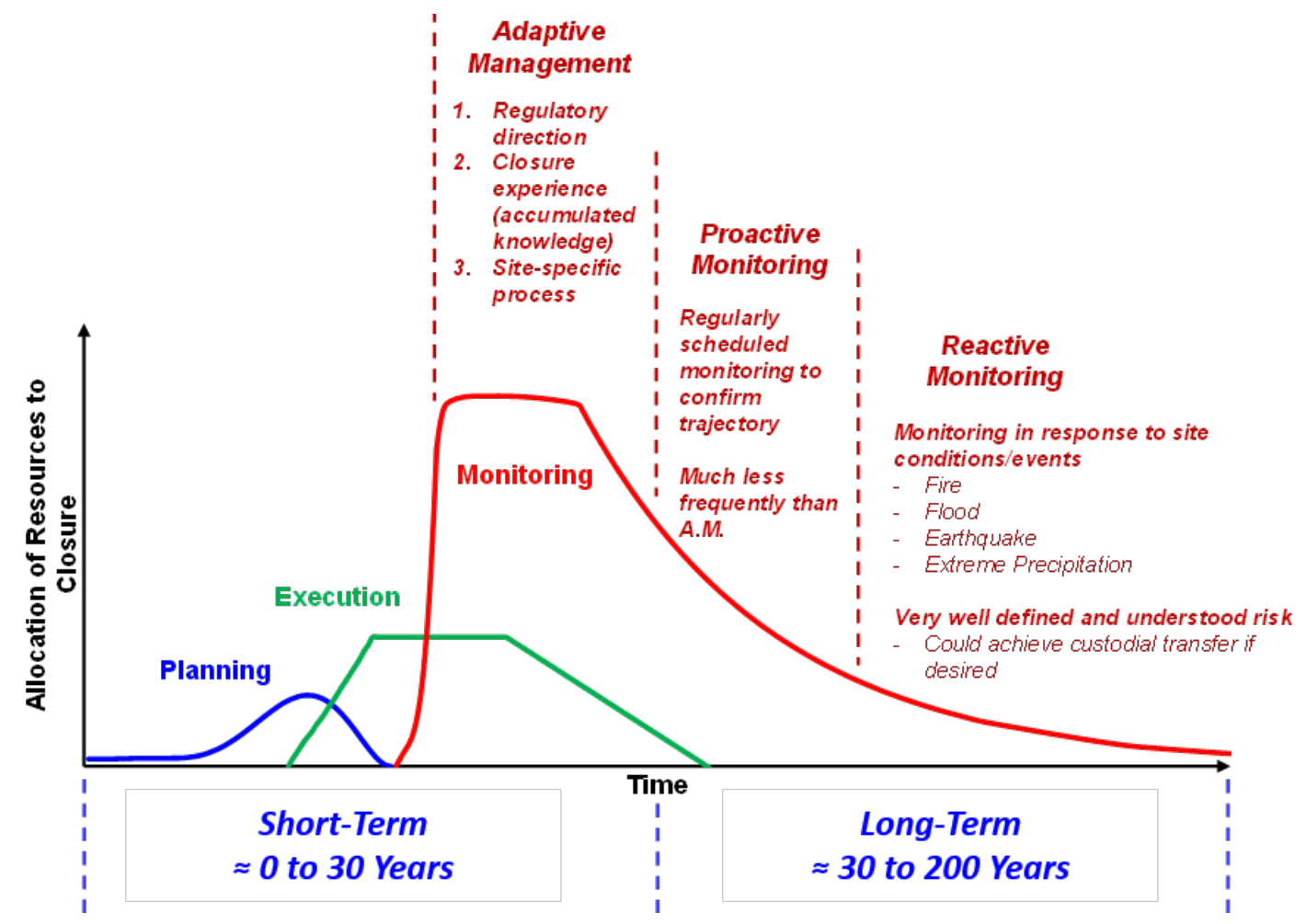

Figure 6 Time frame defined for the FMEA

Further to defining adaptive management, it was agreed during the FMEA workshop that 'true' adaptive management must be adopted in order to properly address risks during this phase of closure, which will allow for appropriate risk evaluation for the same failure mode in the long-term. For example, with 'true' adaptive management, there is a commitment to:

- Utilise the observational method for monitoring during this phase.

- Develop conceptual models for performance.

- Design for the most likely conditions.

- Identify all failure modes (and effects and pathways).

- Develop actual, available, allowable, and cost-effective contingencies for all identified risks.

- Develop designs that address these contingencies, which are put in place upfront and as part of the overall design.

- Monitor closely and frequently to address issues such that contingencies can be implemented before being non-compliant.

- Implement mitigation measures as needed and in a timely manner.

- Undertake regular audits against the performance and compliance program.

- Scan for opportunities to continually improve. 


\subsection{Risk definition}

An FMEA is a methodology for assessment of risk, which is a combination of likelihood and consequences of failure. Risk encompasses both the likelihood of failure or expected frequency of failures, and the severity of expected consequences if such failures were to occur. It is an imprecise process as it requires participants to assess risks into the future; however, there is a difference between the risk of failure and uncertainty in the estimate of that risk. Similar uncertainties are associated with the expected frequency and expected consequence of a risk.

The risk matrix defined for the workshop combined the likelihood of occurrence with the severity of effects for each failure mode and assigned it a risk level ranging from low (1) to critical (5) (Figure 7). The Mine's likelihood and consequence / severity categories were integrated for FMEA in order to better represent The Mine's risk profile, and to stay within The Mine's framework for easy dissemination of information internally. The 'High' and 'Critical' risk levels should be viewed as unacceptable and steps taken to reduce those risks. The 'Moderate' and 'Moderately High' levels are acceptable if they were 'As Low as Reasonably Practical' (ALARP). A risk is ALARP if the cost involved in reducing the risk further is grossly disproportionate to the benefit gained. The 'Low' risk designation is broadly acceptable.

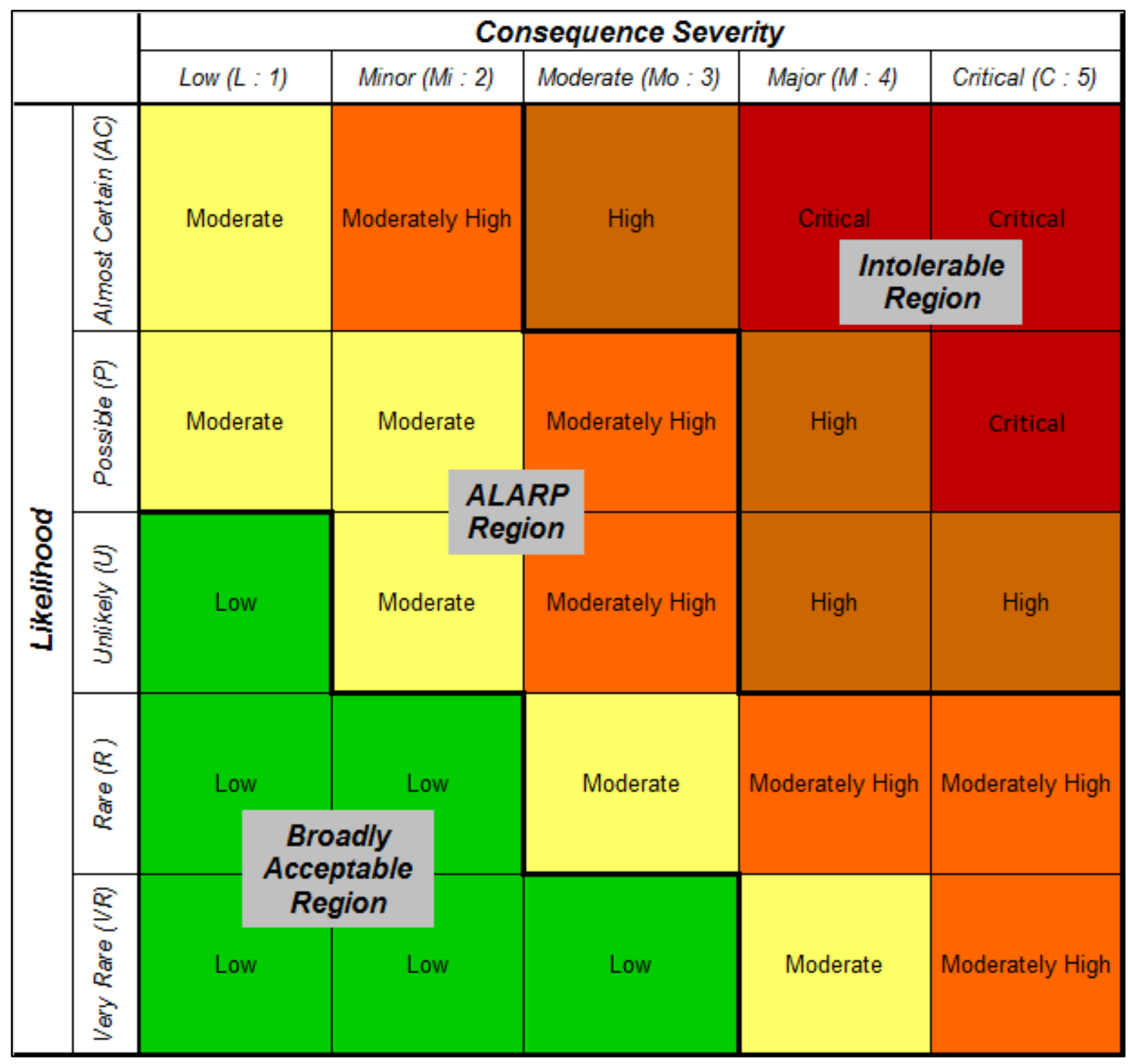

Figure 7 Risk matrix defined for the failure modes and effects analysis workshop 


\subsubsection{Likelihood definition}

A quantitative likelihood approach (Table 3) was used during the FMEA workshop for risk evaluation, with the actual chance of occurrence being dependent on the time frame being evaluated (i.e. short-term or longterm). The risk likelihood scale was adapted to suite The Mine's risk profile for assessing event risks resulting in easy integration into The Mine's framework. In other words, likelihood classes and percentage cut-offs from 0-60\% remained unchanged, however, the four cut-offs on The Mine's scale for $>60 \%$ were integrated into one category.

Table 3 Likelihood of occurrence for environmental and public concern consequences over the failure modes and effects analysis assessment period of 200 years

\begin{tabular}{ll}
\hline Likelihood class & $\begin{array}{l}\text { Likelihood of occurrence for environmental } \\
\text { and public concern consequences }\end{array}$ \\
\hline Very rare (VR) & $<2 \%$ chance of occurrence \\
Rare (R) & $2-20 \%$ chance of occurrence \\
Unlikely (U) & $20-40 \%$ chance of occurrence \\
Possible (P) & $40-60 \%$ chance of occurrence \\
Almost certain (AC) & $>60 \%$ chance of occurrence \\
\hline
\end{tabular}

\subsubsection{Consequences/severity of effect definitions}

The consequence/severity of specific failure modes was assessed based on an evaluation of expected responses following failure. Adverse effects may have physical, biological, health and/or safety consequences. The estimate of consequences is based on the professional judgement of participants and the anticipated impact of that failure, with the chosen ranking based on the consensus of the workshop participants. The Mine's consequence and severity categories were integrated into the FMEA in order to better represent its risk profile, and to stay within The Mine's framework for easier communication within the company.

\subsubsection{Confidence level definition}

Workshop participants developed a consensus on the level of confidence for the risk ranking determined for each failure mode and effects pathways. This level of confidence varied based on the knowns and unknowns at the site, and the failure mechanism. The level of confidence of participants for each evaluation was identified and documented using the designations described in Table 4.

Table 4 Confidence level categories designated by workshop participants

\begin{tabular}{ll}
\hline Confidence & Description \\
\hline Low (L) & $\begin{array}{l}\text { Do not have confidence in the estimate or ability to control during } \\
\text { implementation. }\end{array}$ \\
Medium (M) & $\begin{array}{l}\text { Have some confidence in the estimate or ability to control during } \\
\text { implementation, conceptual level analyses. }\end{array}$ \\
High (H) & $\begin{array}{l}\text { Have lots of confidence in the estimate or ability to control during } \\
\text { implementation, detailed analyses following a high standard of care. }\end{array}$ \\
\hline
\end{tabular}




\section{$4 \quad$ FMEA outcomes to manage the risk}

The FMEA workshop quantified risk and prioritised management actions required to mitigate those risks for closure of the MRS in question within five years. Outcomes from the FMEA workshop were intentionally collaborative as it provided a platform for discussion and debate, leading to outcomes upon which all participants agreed. Outcomes included the development and refinement of the Base Case landform and cover design, and mitigation measures addressing identified failure modes in order to increase the likelihood of attaining closure objectives. The FMEA highlighted numerous overarching concepts and potential failure modes regarding the closure design of the MRS. The formalisation of key concepts were used guide short-term management actions aimed to address failure modes requiring immediate attention.

\subsection{FMEA outcomes - overarching findings}

During the workshop participants agreed that results from the material characterisation program, specifically sulphur speciation work on the MRS provided strong evidence for the presence of large stored oxidation products in a solubility-controlled system. That is, the mobilisation of stored acidity is dependent on the level of saturation (porewater flow rates) within the MRS. Moreover, porewater flow rates are influenced by NP rates where lower NP will generally decrease acidity mobilisation for a longer period, while higher NP will generally increase acidity mobilisation for a shorter period. Overall, seepage is expected to occur regardless of the cover system alternative and/or geometry utilised at the MRS; however, the chosen alternative will have an influence on the timing and rate of mobilised acidity.

Participants agreed that a cover system that decreases NP, hence decreased acid mobility and seepage from the MRS should be constructed. The cover system should contain materials with texture capable of providing sufficient moisture content to sustain vegetation species resembling surrounding areas. They also agreed that cover system material texture, depth, and vegetation establishment are key to reducing NP, and therefore mobilisation of acidity and seepage.

A consensus from the workshop was the fundamental need to further understand the wetting-up evolution of the MRS to implement practical, effective, and timely closure planning management measures. The timing and rate of seepage is largely dependent on the wetting-up/drain-down evolution of the MRS. Moreover, in large MRSs such as the one evaluated, the time required to fully wet up across the full depth of the MRS can take decades. Noting however, that toe and basal seepage can still occur prior to a fully wetted-up condition as sections with less waste depth will wet up sooner (e.g. under sloping surfaces) than those with greater waste depths (e.g. middle of the MRS).

\subsection{Managing the risks}

Formalisation and broad acceptance of the overarching findings led to the discussion and formulation of short-term technical action items with potential to mitigate identified risks. In some instances, technical failure modes fell into more than one technical action item category. A summary of four key failure modes and associated three technical action items intended to mitigate risks associated with the base case landform and cover system are presented in Table 5. Okane is currently completing or have completed several of the technical action items. 
Table 5 Four key failure modes identified during the failure modes and effects analysis, and three associated action items Okane are/have completed and their intention

\begin{tabular}{|c|c|c|c|}
\hline Failure mode & Technical action item & Action item intention & Status \\
\hline $\begin{array}{l}\text { - The average } \\
\text { sulphur grade for } \\
\text { existing acidity used } \\
\text { to predict acidity is } \\
\text { higher than } \\
\text { modelled. } \\
\text { - An increase in } \\
\text { stored oxidation } \\
\text { products, NP, and } \\
\text { temperature occur } \\
\text { during landform } \\
\text { reshaping. }\end{array}$ & - Shallow drilling of MRS surface. & $\begin{array}{l}\text { - Intended to refine stored } \\
\text { acidity estimates required for } \\
\text { closure planning and evaluate } \\
\text { the gas risk associated with } \\
\text { landform reshaping. }\end{array}$ & Completed \\
\hline $\begin{array}{l}\text { - The average } \\
\text { sulphur grade for } \\
\text { existing acidity and } \\
\text { used to predict } \\
\text { future additional } \\
\text { acidity is higher } \\
\text { than modelled. } \\
\text { - An increase in } \\
\text { stored oxidation } \\
\text { products, NP, and } \\
\text { temperature, occur } \\
\text { during landform } \\
\text { reshaping. }\end{array}$ & $\begin{array}{l}\text { - Further drilling, material } \\
\text { characterisation, and downhole } \\
\text { instrumentation of the MRS to } \\
\text { further understand the stored } \\
\text { acidity risk and monitor in situ } \\
\text { water and temperature } \\
\text { conditions to understand the } \\
\text { volume, concentration, and } \\
\text { timing of potential seepage. }\end{array}$ & $\begin{array}{l}\text { - Intended to refine the MRS } \\
\text { wetting status to improve } \\
\text { understanding for timing and } \\
\text { volume of seepage release. }\end{array}$ & Ongoing \\
\hline $\begin{array}{l}\text { - Poor vegetation } \\
\text { establishment } \\
\text { and/or mortality on } \\
\text { the cover system } \\
\text { due to a lack of } \\
\text { moisture availability } \\
\text { in the short-term. } \\
\text { - Predicted positive } \\
\text { influence of } \\
\text { vegetation on } \\
\text { reducing NP is not } \\
\text { achieved. }\end{array}$ & $\begin{array}{l}\text {-An improved understanding of } \\
\text { plant moisture requirements as a } \\
\text { function of cover material } \\
\text { physical characteristics through } \\
\text { vegetated cover trials and } \\
\text { quantification of plant } \\
\text { characteristics on previously } \\
\text { rehabilitated areas. } \\
\text { - The selection of cover material } \\
\text { that has adequate water holding } \\
\text { capacity to support plant } \\
\text { moisture requirement, and/or } \\
\text { the selection of species that are } \\
\text { best suited to the cover material } \\
\text { physical characteristics should } \\
\text { improve the establishment } \\
\text { success of vegetation during the } \\
\text { short- and long-term. }\end{array}$ & $\begin{array}{l}\text { - Improving/optimising } \\
\text { vegetation establishment } \\
\text { success and survival by } \\
\text { addressing knowledge gaps } \\
\text { associated with plant moisture } \\
\text { requirements and material } \\
\text { characteristics to achieve the } \\
\text { revegetation closure objective. }\end{array}$ & Ongoing \\
\hline
\end{tabular}




\section{$5 \quad$ Closure}

Okane have worked with The Mine for 20 years to assist in building an understanding of the legacy issues originating from before the 1990's that were associated with a lack of AMD prediction, historic dumping practices, and lack of engineering controls for oxygen and water. Evidence of PAF material reactivity was recognised early resulting in the identification of potential risks most notably high internal temperatures resulting in gas release and AMD thus guiding preliminary technical studies. Preliminary studies included the construction of instrumented cover systems as a means of limiting oxygen ingress and NP. An MRS drilling program was also completed to quantify the structure, reactivity and hydrology of the MRS. During drilling the MRS internal structure was characterised and instrumented with gas and moisture sensors to quantify MRS reactivity and moisture conditions in response to environmental factors over time. These investigations led to significant advancements in the understanding of the MRS conditions, construction, sulphide oxidation, and associated risks.

Using the FMEA process Okane were able to effectively quantify and communicate the risk associated with the closure of a large MRS at an iconic mine in the Pilbara region of WA. Overarching concepts driving the risk and alterations to the base case landform design and cover system were agreed by all expert participants during the workshop. Effective communication of risks, and identification of failure modes and effects resulted in the identification of technical action items that could be completed to mitigate risks. Action items fit within the short-term time frame ( $<30$ years), and within the five-year closure time frame of the MRS resulting in a cost savings of 25 times the cost compared to if earthworks were to occur outside five years. Closure solutions are specific to the company's closure criteria and risk profile ultimately resulting in mitigation of risks and long-term cost minimisation for closure.

\section{References}

Cavanagh, J, Pope, J, Simcock, R, Harding, J, Trumm, D, Craw, D,...\& Simon, K 2018, Mine environment life-cycle guide: potential acidforming and non-acid-forming coal mines, Centre for Minerals Environmental Research, Otago, https://www.cmer.nz/publications/2018/MELG_Coal_PAFV1.2.pdf

Commonwealth of Australia 2019, Rehabilitation of mining and resources projects and power station ash dams as it relates to Commonwealth responsibilities, Senate Printing Unit, Canberra.

Department of Mines and Petroleum 2018, Western Australia mineral and petroleum statistics digest 2017-2018, Government of Western Australia, Perth.

Environmental Protection Authority 2014, Cumulative environmental impacts of development in the Pilbara region: advice of the Environmental Protection Authority to the minister for environment under Section 16(e) of the Environmental Protection Act 1986, Government of Western Australia, Perth.

International Network for Acid Prevention 2017, Global cover system design - Technical guidance document, Victoria, https://www.inap.com.au/research/\#globalCoverSystem

Pearce, S \& Barteaux, M 2014, 'Instrumentation in waste rock dumps: Going deeper', in eds. H Hiller and L Preuss (eds.), Proceedings of the Eighth Australian Workshop on Acid and Metalliferous Drainage, JKTech Pty Ltd., Adelaide, pp. 371-386.

Peel, MC, Finlayson, BL \& Mcmahon, TA 2007, 'Updated world map of the Köppen-Geiger climate classification', Hydrology and Earth System Sciences Discussions, vol. 11, no. 5, pp. 1633-1644.

Singh, RN 1999, 'Environmental catastrophes in the mining industry in Australia and the development of current management practices', Journal of Mines, Metals and Fuels, vol. 47, No. 12, pp. 339-343. 
